\title{
BMJ Open Prevalence of overweight/obesity among the adult population in Ethiopia: a systematic review and meta-analysis
}

\author{
Ayelign Mengesha Kassie (D), Biruk Beletew Abate (D), Mesfin Wudu Kassaw
}

To cite: Kassie AM, Abate BB, Kassaw MW. Prevalence of overweight/obesity among the adult population in Ethiopia: a systematic review and meta-analysis. BMJ Open 2020;10:e039200. doi:10.1136/ bmjopen-2020-039200

- Prepublication history and additional material for this paper are available online. To view these files, please visit the journal online (http://dx.doi. org/10.1136/bmjopen-2020039200).

Received 13 April 2020 Revised 12 June 2020 Accepted 17 June 2020

Check for updates

(C) Author(s) (or their employer(s)) 2020. Re-use permitted under CC BY-NC. No commercial re-use. See rights and permissions. Published by BMJ.

Department of Nursing, Woldia, College of health sciences, Woldia University, Woldia, Amhara, Ethiopia

\section{Correspondence to} Mr Ayelign Mengesha Kassie; Ayelignmengesha59@gmail. com

\section{ABSTRACT}

Background Overweight and obesity are emerging public health problems in Ethiopia. However, primary study findings on the prevalence of overweight and obesity in Ethiopia are inconsistent. Therefore, this study aimed to estimate the pooled prevalence of overweight and obesity among adults in Ethiopia.

Methods Studies that looked at overweight and obesity among adults were searched from four international databases. The search involved articles published from 1 January 2010 to 10 March 2020. The Cochran's $Q \chi^{2}$ and the $\mathrm{I}^{2}$ test statistics were used to check heterogeneity among the studies. The funnel plot and Egger's regression tests were also used to assess the presence of publication bias. Subgroup analysis was performed by residence, study setting, sample size and year of study. Sensitivity analysis was also done to assess the effect of a single study on the pooled estimates. Data analysis was done using STATA V.14 software program.

Results A total of 16 studies with 19527 study participants were included in this systematic review and meta-analysis. The estimated pooled prevalence of overweight among adults in Ethiopia was $20.4 \%$, and after adjustment for publication bias with the trim-and-fill analysis, the estimated prevalence rate was changed to $19 \%$. Besides, the estimated pooled prevalence of obesity was $5.4 \%$. The prevalence of overweight was higher, $22.6 \%$ in studies published since $2015,22.4 \%$ in studies conducted only in urban settings and $24.4 \%$ in studies with small sample size ( $\leq 384$ participants). Similarly, the prevalence of obesity was $6.9 \%$ in studies published since $2015,6.2 \%$ in studies conducted only in urban settings, $6.4 \%$ in institution-based settings and $9.6 \%$ in studies with small sample size.

Conclusion The prevalence of overweight and obesity is high in Ethiopia compared with previous studies. This needs large scale awareness creation campaigns and situation-based and context-specific prevention strategies.

\section{INTRODUCTION}

Overnutrition is becoming a major public health problem globally. Overweight, obesity and diet-related non-communicable diseases are included under problems of overnutrition. ${ }^{1}$ Overweight and obesity are used to refer an abnormal or excessive fat accumulation that can put people at greater risk and may impair their health. ${ }^{2}$

\section{Strengths and limitations of this study}

- The study has used a prespecified protocol for search strategy and data abstraction and used internationally accepted tools for a critical appraisal system for quality assessment of individual studies.

- It is difficult to determine if the results from various regions are representative of the entire country, as no data were found for all regions of the country.

- Furthermore, the majority of the studies were conducted in urban settings and only two studies were obtained involving participants from both rural and urban settings. Hence, the results may not truly reflect the rural population of Ethiopia.

Obesity is considered an illness that necessitates immediate reversal to prevent early and untimely death among patients. Because people with obesity are more likely to have other diseases including type 2 diabetes, high blood pressure, sleep apnoea and many more. $^{34}$

Overweight and obesity affect all age groups of people both in developed and low/ middle-income countries regardless of their socioeconomic status. ${ }^{15}$ Since 1980; the prevalence of obesity has doubled in more than 70 countries and has continuously increased in most other countries. ${ }^{6}$

In 2016, more than 1.9 billion adults were overweight worldwide. Of these, over 650 million were obese. Overweight accounted for $39 \%$ (39\% of men and $40 \%$ of women), and obesity $13 \%$ ( $11 \%$ of men and $15 \%$ of women) in the same year. ${ }^{7}$

The prevalence of overweight and obesity is escalating in low/middle-income countries, particularly among urban dwellers and wealthier people due to the influence of demographic, epidemiological and nutrition transitions. ${ }^{8}$ According to a study conducted in 2013 on the global trends of overweight and obesity, $26.9 \%$ of adults in Africa are overweight and obese. ${ }^{9}$ 
Overweight and obesity in adults are associated which increased risk of diabetes, hypertension and other chronic diseases. In addition to these chronic diseases, overweight and obesity in women increases the risk of caesarean section delivery, postpartum haemorrhage, high birthweight babies, and infant overweight and obesity. ${ }^{110}$

The latest WHO reports showed that overweight and obesity are becoming the leading causes of death worldwide. ${ }^{11}$ In 2015, high body mass index (BMI) has caused an estimated 4 million deaths globally, and nearly $40 \%$ of these deaths occurred in persons who were overweight but not obese. More than two-thirds of the deaths related to high BMI were due to cardiovascular diseases. ${ }^{6} 12$

Overweight and obesity cost the world billions of dollars a year in lost opportunities for economic growth and lost investments in human capital associated with the increased preventable morbidity and mortality rates in both children and adults. ${ }^{13}$

Like other countries, the burden of overweight and obesity is becoming a major problem in Ethiopia. According to the 2016 Ethiopian demographic and health survey report, the proportion of overweight and obesity among women has increased from 3\% in 2000 to $8 \%$ in 2016 . Similarly, $3 \%$ of men were overweight or obese in $2016 .{ }^{14}$

Overweight and obesity are associated with many factors including excessive consumption of alcohol, cigarette smoking and sedentary lifestyle habits. ${ }^{15}$ Some studies have also reported that the risk of overweight and obesity is increased with education ${ }^{16}{ }^{17}$ and wealth in low/middle-income countries. ${ }^{18-20}$

As a treatment, behavioural and pharmaceutical interventions are available and helpful in getting weight loss. A reduction of $5 \%-7 \%$ of body weight alone is associated with a lower incidence of diabetes, hypertension and other cardiovascular diseases. Larger weight loss has even been linked with better improvements in controlling the level of blood glucose and lipids in limited surgical outcomes data. ${ }^{21}$

Therefore, knowing the prevalence of overweight and obesity is paramount to design preventive strategies. However, there is no national study on the prevalence of overweight and obesity in the general adult population of Ethiopia. Furthermore, findings from small studies are inconsistent with the combined prevalence of overweight and obesity reported ranging from $4.5 \%^{22}$ to $21.4 \%^{23}$ in the country. Hence, this systematic review and meta-analysis aimed to determine the pooled prevalence of overweight and obesity among adults in Ethiopia.

\section{METHODS}

Literature search strategy

First, The Cochrane Library, Joanna Briggs Institute (JBI) and PROSPERO databases were searched to check whether a systematic review and meta-analysis studies exist or for the presence of ongoing projects related to overweight and obesity in Ethiopia. The necessary articles were searched using PubMed, Scopus, Google scholar and African journals online.

For this study relevant, articles were identified using the following terms:"overweight", "obesity", "nutrition", "malnutrition", "undernutrition", "over nutrition", "adults", "elders", "geriatrics" and "Ethiopia". The key terms were used in combination using Boolean operators like "OR" or "AND". The searches were restricted to full texts, free articles, human studies and English language publications. This search involved articles published from 1 January 2010 to 10 March 2020.

Grey literatures like surveillance reports, academic dissertations and conference abstracts were also examined and included when they deemed low risk. Besides, the reference lists of included articles in this systematic review and meta-analysis were hand-searched to identify any relevant additional articles.

\section{PubMed search strategy}

$((((()((()($ overweight $))$ OR (obesity) $)$ OR (nutrition $))$ OR (malnutrition)) OR (overnutrition)) OR (undernutrition)) AND (Adults)) OR (Elders)) OR (Geriatrics)) AND (Ethiopia)) AND ((“2010/01/01”[Date - Entry]: “2020/10/03”[Date - Entry])). Filters applied: Free full text, in the last 10 years.

\section{Eligibility criteria}

Studies were included in this systematic review and metaanalysis if they followed the following guidelines ${ }^{1}$ : all observational study designs (cross-sectional, case-control and cohort studies) which reported the prevalence of overweight and obesity or one of them; ( 2 published from 2010 to $2020^{3}$; published in the English language ${ }^{4}$; abstract and, or full text available for this review; $a^{5} d^{5}$ conducted in Ethiopia. Studies were excluded if they ${ }^{1}$ : possessed a poor quality score as per the stated criteria ${ }^{2}$; failed to determine the desired outcomes (overweight and obesity) and ${ }^{3}$ included children and adolescents. It was considered that the exclusion of articles published in other languages due to translation issues might create language bias. However, no articles published in other languages including the Amharic language were obtained during the search period.

\section{Outcomes of interest}

The main outcomes of interest were the prevalence of overweight and obesity reported in the original papers either as a percentage or as the number of cases $(n) /$ total number of study participants $(\mathrm{N})$. These two parameters were necessary to calculate the pooled prevalence of overweight and obesity in the meta-analysis. Therefore, the prevalence rate was calculated by dividing the number of individuals who were overweight and, or obese to the total number of study participants (sample size) multiplied by 100 . 


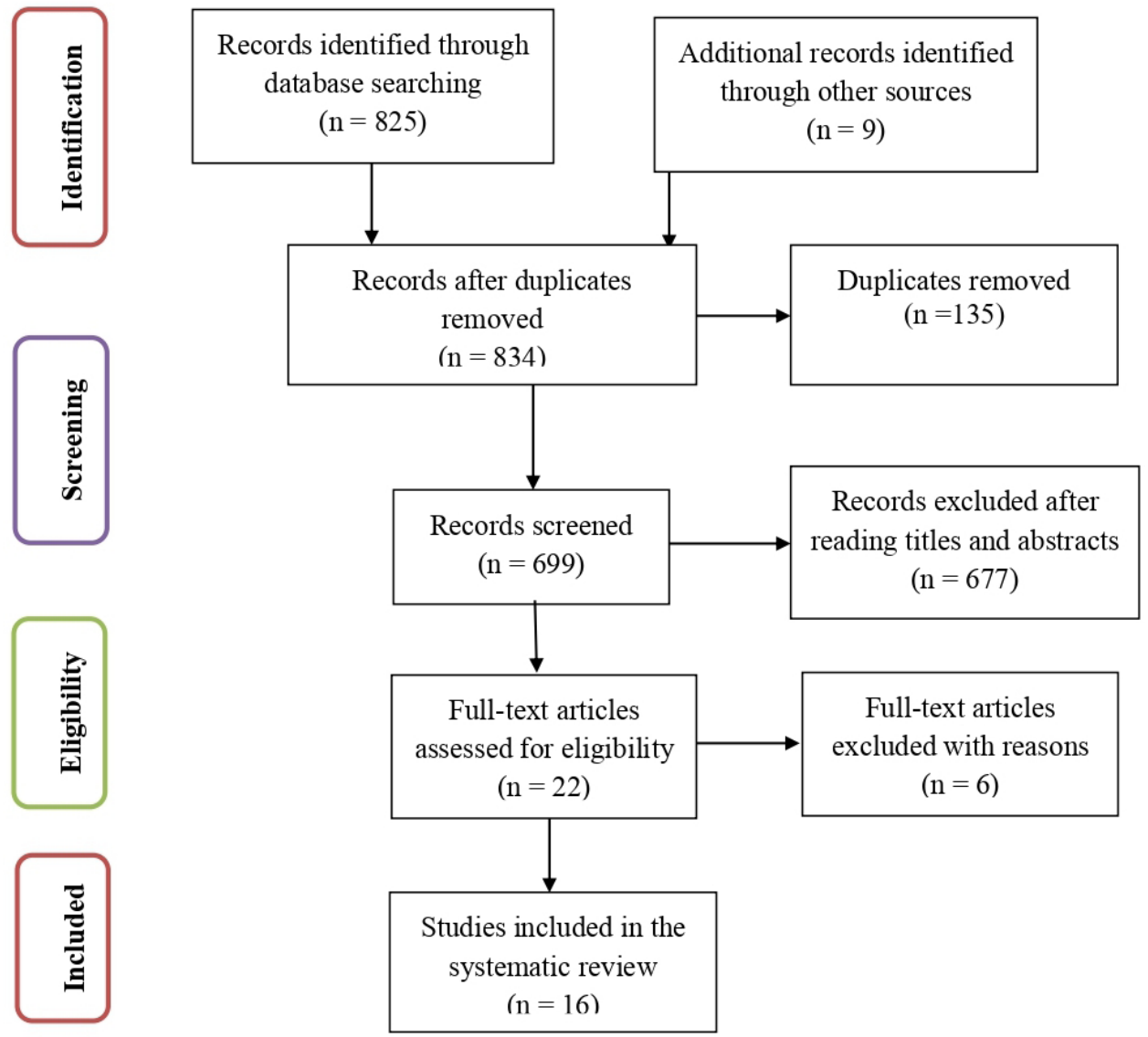

Figure 1 PRISMA flow chart of study selection for the prevalence of overweight and obesity among adults in Ethiopia. PRISMA, Preferred Reporting Items for Systematic Reviews and Meta-Analyses statement.

The outcome variables of interest were categorised as follows based on the WHO Classification of BMI; overweight if the BMI is $25.0-29.9 \mathrm{~kg} / \mathrm{m}^{2}$ and obese if it is $\geq 30.0 \mathrm{~kg} / \mathrm{m}^{2}$ for the study participants of the included studies in the systematic review and meta-analysis. ${ }^{24}$

\section{Data extraction}

The authors developed a data extraction form on the excel sheet which includes the author name, year of publication, study setting, study design, sex of participants, sample size and the prevalence of overweight and obesity. The data extraction sheet was piloted using five papers randomly. The extraction form was adjusted after having a piloted template.

Two of the authors independently extracted all the necessary data from each study using the data extraction format. The third author checked the correctness of the data independently. Any disagreements between authors who extracted the data were resolved through discussions with the third reviewer and fourth reviewer when required. For articles that did not provide details of their study background, corresponding authors were contacted through email and asked for the relevant information, such as study time, region or others.

\section{Quality assessment}

Two independent authors assessed the methodological quality of all of the potential studies to be included in the analysis. Any disagreements between the authors were resolved through discussion or, if consensus could not be reached, consultation with a third independent author was considered. The quality of each included study was assessed using the JBI quality appraisal checklist for crosssectional studies. ${ }^{25}$ Because the articles included in this study were all cross-sectional. Studies were considered low risk when scored $50 \%$ and above of the JBI quality assessment indicators.

\section{Patient and public involvement}

No patient involved.

\section{Statistical analysis}

To obtain the pooled prevalence of overweight and obesity, a meta-analysis using the random-effects model was performed due to the presence of heterogeneity. ${ }^{26}$ Cochran's $\mathrm{Q} \chi^{2}$ statistic and the $\mathrm{I}^{2}$ tests were run to assess the random variations between primary studies. The $\mathrm{I}^{2}$ test is used to indicate the percentage of variance in a meta-analysis that is attributable to heterogeneity among the studies. ${ }^{27}$ In this study, heterogeneity was interpreted as an $\mathrm{I}^{2}$ value of $0 \%=$ no heterogeneity, $\leq 25 \%=$ low, $25 \%-50 \%=$ moderate, $50-75=$ substantial and $\geq 75 \%=$ high level heterogeneity. ${ }^{27}$ In the case of high heterogeneity, subgroup and sensitivity analyses were run to identify possible moderators for the heterogeneity. 


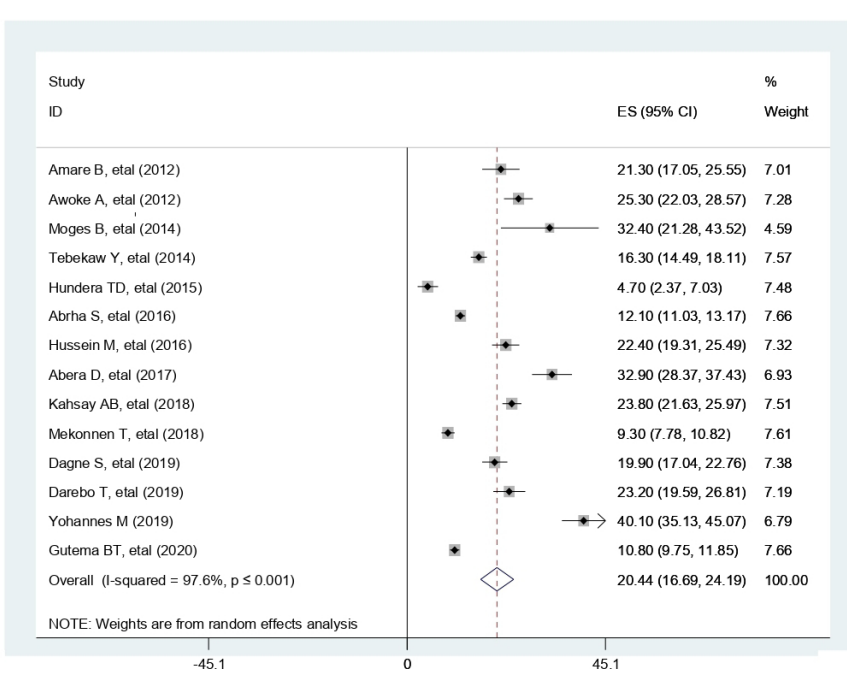

Figure 2 Forest plot for the prevalence of overweight among adults in Ethiopia. ES, effect size.

\section{Publication bias}

Methods of avoiding publication bias like identifying and including unpublished studies, meeting abstracts and dissertations were considered. Furthermore, potential publication bias was assessed by visually inspecting the funnel plots and objectively using the Egger's bias test during analysis. ${ }^{28}$ The trim-and-fill analysis was also done to assess for and adjust any publication bias based on the assumption that the effect sizes of all the studies are normally distributed around the centre of a funnel plot in the absence of publication bias.

The trim-and-fill method is used to first trim the studies that cause asymmetry in the funnel's plot so that the overall effect estimate produced by the remaining studies can be considered minimally affected by publication bias, and then to fill imputed missing studies in the funnel plot based on the bias-corrected overall estimate. ${ }^{29}$ The metaanalysis was performed using the STATA V.14 software program. ${ }^{30}$ Finally, for all analysis, a $\mathrm{p}<0.05$ was considered to declare statistically significant values.

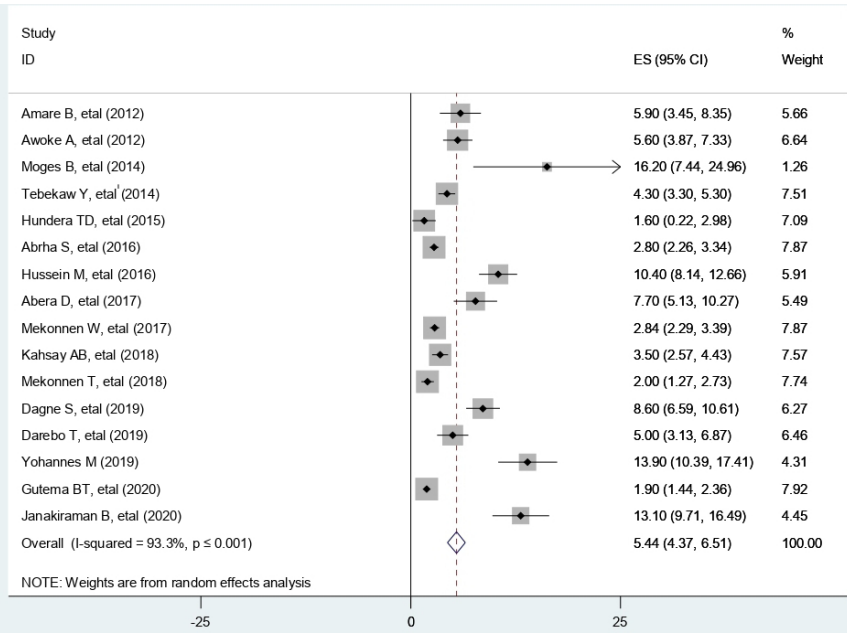

Figure 3 Forest plot for the prevalence of obesity among adults in Ethiopia. ES, effect size.

\section{Presentation and reporting of results}

The results of this systematic review and meta-analysis were reported based on the Preferred Reporting Items for Systematic Reviews and Meta-Analyses statement (PRISMA) guideline. ${ }^{31}$ The entire process of study screening, selection and inclusion are shown with the support of a flow diagram. Moreover, tables and narrative summaries are used to report the risk of bias for every eligible study.

\section{RESULTS}

\section{Search results}

A total of 834 articles were retrieved from international databases and grey literatures. In the first step of article searches, 825 studies that were published from 2010 to 2020 were retrieved through database searching from four international databases. On the other hand, the remaining nine studies have been obtained from other sources including grey literatures.

Of these studies, 135 duplicate records were identified and after duplication removal, a total of 699 articles remained. Then, 677 articles were excluded after reading the title and or the abstract because either they were not conducted in Ethiopia or they were not in line with the objective of this systematic review and meta-analysis.

Finally, 22 studies were screened for full-text review and, 16 articles ( $\mathrm{n}=19527$ participants) were selected to estimate the pooled prevalence of overweight and obesity among adults in Ethiopia. The remaining six studies were excluded because they failed to report the prevalence of overweight and obesity separately (they only reported a combined prevalence of overweight and obesity). The detailed steps in the screening process are shown in the PRISMA flow chart of the study selection (figure 1).

\section{Baseline characteristics of included studies}

In the current meta-analysis, a total of 16 studies with 19527 study participants were included to estimate the pooled prevalence of overweight and obesity among adults in Ethiopia. Among these studies, 14 had reported the prevalence of both overweight and obesity, and 2 studies had reported the prevalence of obesity only. Concerning the study design, all of the studies included were cross-sectional. The studies included in this systematic review and meta-analysis varied significantly in sample size ranging from 68 (the small) to 6602 (the large).

Overall information regarding the prevalence of overweight and obesity among adults was obtained from various regions in the country. Six of the studies involved participants from Amhara, ${ }^{32-37}$ four from Southern Nations, Nationalities, and People's Region, ${ }^{38-41}$ one from Oromia ${ }^{42}$ one from Somali ${ }^{43}$ one from Tigrai, ${ }^{44}$ one from Addis $\mathrm{Ababa}^{45}$ and two studies involving participants from the different regions. ${ }^{46} 47$

Regarding sampling, all of the studies had used the probability sampling technique. The quality score of each primary study as evaluated based on the JBI quality 
Table 1 Prevalence of overweight and obesity in Ethiopia after subgroup analysis by characteristics of the studies included

\begin{tabular}{|c|c|c|c|c|c|c|}
\hline Subgroup & $\begin{array}{l}\text { No of } \\
\text { studies }\end{array}$ & $\begin{array}{l}\text { Overweight } \\
(95 \% \mathrm{Cl})\end{array}$ & $I^{2}$ and $p$ value & $\begin{array}{l}\text { No of } \\
\text { studies }\end{array}$ & Obesity $(95 \% \mathrm{Cl})$ & $I^{2}$ and $p$ value \\
\hline \multicolumn{7}{|l|}{ Year of study } \\
\hline Before 2015 & 6 & 17.49 (12.17 to 22.81$)$ & $(96.5 \%, p \leq 0.001)$ & 7 & 3.74 (2.73 to 4.75$)$ & $(82.3 \%, p \leq 0.001)$ \\
\hline After 2015 & 8 & 22.55 (16.57 to 28.54$)$ & $(98.2 \%, p \leq 0.001)$ & 9 & 6.90 (4.89 to 8.92$)$ & $(95.8 \%, p \leq 0.001)$ \\
\hline \multicolumn{7}{|l|}{ Residence } \\
\hline Urban & 12 & 22.43 (17.76 to 27.10$)$ & $(97.4 \%, p \leq 0.001)$ & 14 & $6.23(4.92$ to 7.54$)$ & $(92.6 \%, p \leq 0.001)$ \\
\hline Both & 2 & 10.15 (8.70 to 11.61$)$ & $(60.5 \%, p \geq 0.05)$ & 2 & 1.93 (1.54 to 2.32$)$ & $(0.0 \%, p \geq 0.05)$ \\
\hline \multicolumn{7}{|l|}{ Setting } \\
\hline Community based & 9 & 19.46 (15.93 to 23.00$)$ & $(95.8 \%, p \leq 0.001)$ & 10 & 5.13 (3.90 to 6.35$)$ & $(92.9 \%, p \leq 0.001)$ \\
\hline Institution based & 5 & 20.44 (16.69 to 24.19$)$ & $(98.9 \%, p \leq 0.001)$ & 6 & 6.41 (3.79 to 9.03 ) & $(94.8 \%, p \leq 0.001)$ \\
\hline \multicolumn{7}{|l|}{ Sample size } \\
\hline
\end{tabular}

${ }^{*}$ The terms are self explanatory and no footnotes are added.

appraisal criteria showed no considerable risk; hence, all the studies were included in this systematic review and meta-analysis (online supplementary additional file 1).
The pooled prevalence of overweight among adults in Ethiopia Fourteen studies $(n=14)$ had reported the prevalence of overweight among adults in different regions of Ethiopia

\begin{tabular}{|c|c|c|c|}
\hline tudy ommited & coef. & {$[95 \%$} & Interval] \\
\hline 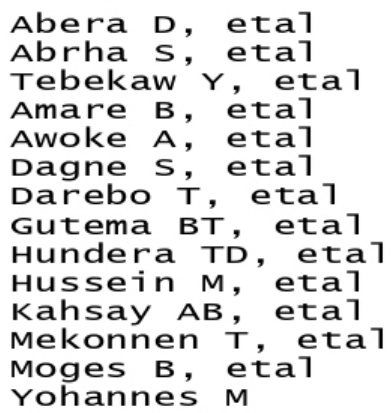 & $\begin{array}{l}19.458002 \\
21.24802 \\
20.829943 \\
20.375648 \\
20.031092 \\
20.491842 \\
20.217529 \\
21.33058 \\
21.686108 \\
20.278517 \\
20.123743 \\
21.394331 \\
19.859375 \\
18.918518\end{array}$ & $\begin{array}{l}15.773933 \\
16.798456 \\
16.721661 \\
16.482386 \\
16.230967 \\
16.559935 \\
16.353727 \\
17.008682 \\
17.891603 \\
16.404625 \\
16.369978 \\
17.333912 \\
16.047747 \\
15.393227\end{array}$ & $\begin{array}{l}23.142069 \\
25.697584 \\
24.938225 \\
24.268913 \\
23.831217 \\
24.42375 \\
24.081333 \\
25.652477 \\
25.480614 \\
24.152409 \\
23.87751 \\
25.45475 \\
23.671003 \\
22.443808\end{array}$ \\
\hline combined & 20.439183 & 16.689844 & 24.188523 \\
\hline
\end{tabular}

Figure 4 Result of sensitivity analysis of the 14 studies in the meta-analysis of overweight.

\begin{tabular}{|c|c|c|c|}
\hline study ommited & coef. & conf. & Interval] \\
\hline 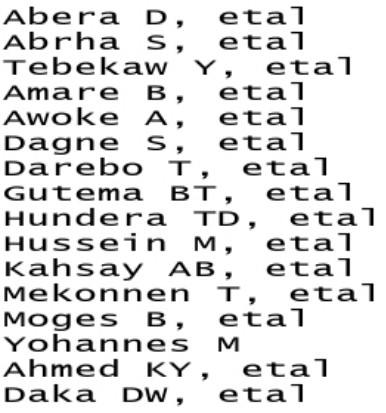 & $\begin{array}{l}5: 2844915 \\
5: 8013558 \\
5: 5626507 \\
5: 4089479 \\
5: 4232454 \\
5: 156126 \\
5: 4749699 \\
5: 832715 \\
5: 748404 \\
5: 0217872 \\
5: 6494417 \\
5: 787991 \\
5: 2873678 \\
4: 9776611 \\
5: 4408903 \\
5.4408903\end{array}$ & $\begin{array}{l}4.2053108 \\
4: 5596724 \\
4: 425869 \\
4: 3111115 \\
4: 3210888 \\
4: 1098514 \\
4: 3657789 \\
4: 6363239 \\
4: 6261935 \\
4: 0067286 \\
4: 4939957 \\
4: 6217656 \\
4: 2271786 \\
3: 9654725 \\
4: 3709903 \\
4.3709903\end{array}$ & $\begin{array}{l}6.3636723 \\
7: 0430388 \\
6: 6994324 \\
6: 5067844 \\
6: 5254025 \\
6: 2024007 \\
6: 5841608 \\
7: 0291057 \\
6: 8706145 \\
6: 0368457 \\
6: 8048878 \\
6: 9542165 \\
6: 3475571 \\
5: 98985 \\
6: 5107903 \\
6: 5107903\end{array}$ \\
\hline combined & 5.4408902 & 4.3709902 & 6.5107903 \\
\hline
\end{tabular}

Figure 5 Result of sensitivity analysis of the 16 studies in the meta-analysis of obesity. 


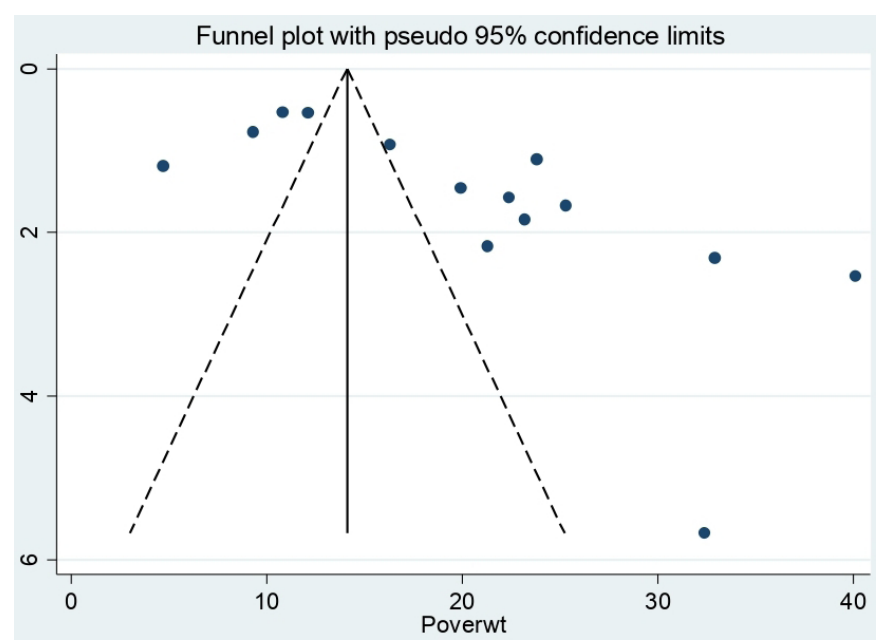

Figure 6 Distribution of studies included in overweight analysis in the funnel graph.

(online supplementary additional file 1 ). The prevalence of overweight reported in the country ranges from $4.7 \%{ }^{42}$ to $40.1 \%{ }^{41}$ The random-effects model analysis from those studies revealed that in this meta-analysis, the estimated pooled prevalence of overweight among adults in Ethiopia was $20.44 \%$ (95\% CI $16.69 \%$ to $24.19 \%$ ) with a significant level of heterogeneity among the studies $\left(\mathrm{I}^{2}=97.6 \%\right.$; $\mathrm{p} \leq 0.001$ ) (figure 2).

\section{The pooled prevalence of obesity among adults in Ethiopia}

Besides overweight, sixteen studies $(n=16)$ had reported the prevalence of obesity among adults in different parts of the country (online supplementary additional file 1 ). The prevalence of obesity reported in the country ranges from $1.6 \%{ }^{42}$ to $16.2 \% .^{34}$ In this meta-analysis, the estimated pooled prevalence of obesity among adults was $5.44 \%(95 \%$ CI $4.37 \%$ to $6.51 \%)$ but with a significant level of heterogeneity among the studies in the randomeffects model analysis $\left(\mathrm{I}^{2}=93.3 \%, \mathrm{p} \leq 0.001\right)$ (figure 3 ).

\section{Subgroup analysis}

There was a significant level of heterogeneity among the primary studies included in this systematic review and meta-analysis. Thus, a subgroup analysis was conducted through stratification using study year, residence, study setting and sample size to identify the sources of heterogeneity for the pooled prevalence of overweight and obesity among adults.

In the subgroup analysis, the prevalence of overweight was found to be $22.55 \%$ in studies published since 2015 , $22.43 \%$ in studies conducted only in urban settings, $20.44 \%$ in institution-based settings and $24.39 \%$ in studies with a sample size of less than or equal to 384 participants. Similarly, the prevalence of obesity was found to be $6.90 \%$ in studies published since $2015,6.23 \%$ in studies conducted only in urban settings, $6.41 \%$ in institutionbased settings and $9.61 \%$ in studies with a sample size of less than or equal to 384 participants (table 1).

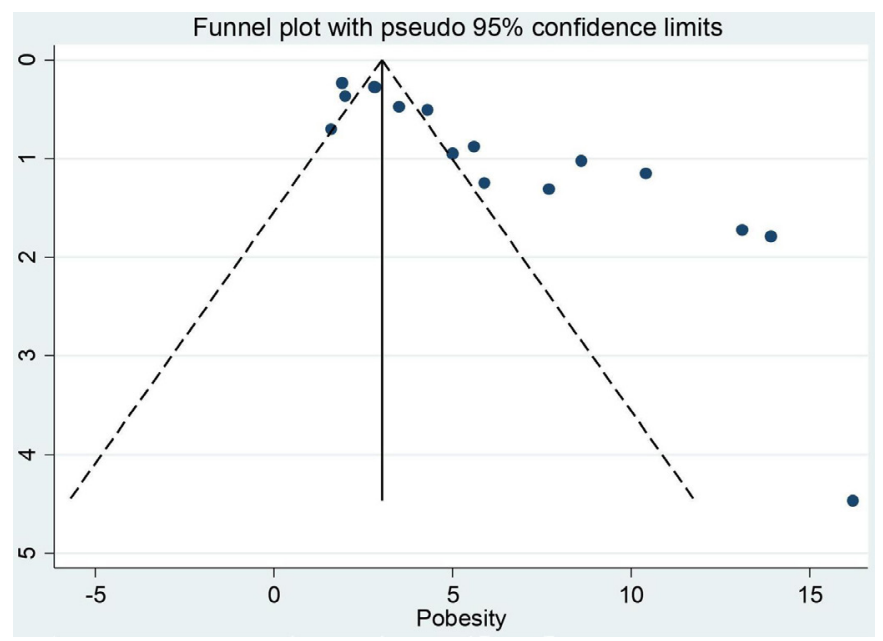

Figure 7 Distribution of studies included in obesity analysis in the funnel graph.

\section{Sensitivity analysis for the prevalence of overweight}

To evaluate the effect of individual studies on the pooled prevalence of overweight among adults in Ethiopia, a sensitivity analysis was performed using the randomeffects model. The results from the sensitivity analysis had revealed that a single study had not influenced the pooled estimated prevalence of overweight among adults. The pooled estimated prevalence of overweight varied between $18.92(15.39,22.44)^{41}$ and $21.69(17.89,25.48)^{42}$ after the deletion of a single study (figure 4 ).

\section{Sensitivity analysis for the studies included in obesity}

To check the effect of individual studies on the pooled prevalence of obesity in Ethiopia, a sensitivity analysis was performed using the random-effects model and the results had revealed that there was no influential study on the pooled estimated prevalence of obesity among adults. The pooled estimated prevalence of obesity ranged from $4.98(3.97,5.99)^{41}$ to $5.83(4.64,7.03)^{40}$ after the deletion of a single study (figure 5).

\section{Publication bias}

There was a publication bias among the included studies in both overweight and obesity as illustrated by the asymmetrical distribution of funnel plot tests (figures 6 and 7). Similarly, the results of Egger's tests for the funnel plot were statistically significant for the presence of publication bias $(p=0.002$ for overweight and $p \leq 0.001$ for obesity), respectively (figures 8 and 9 ).

\section{Trim-and-fill analysis for the prevalence of overweight and obesity}

To reduce and adjust the publication bias in the studies, the trim-and-fill analysis was performed for estimation of the number of missing studies that might exist. During the analysis, only one study was imputed for missing studies and after adjustment for publication bias, the estimated pooled prevalence of overweight among adults in Ethiopia appeared to be 19.02 (95\% CI 15.29 to 22.74) 
Egger's test

\begin{tabular}{r|rrrrrr}
\hline Std_Eff & Coef. & std. Err. & $t$ & P $>|t|$ & [95\% Conf. Interva1] \\
\hline slope & 6.137967 & 2.411285 & 2.55 & 0.026 & .8842288 & 11.39171 \\
bias & 9.04124 & 2.353041 & 3.84 & 0.002 & 3.914404 & 14.16808
\end{tabular}

Figure 8 Egger's test for detection of publication bias for studies included in overweight.

but with a significant level of heterogeneity among the studies $\left(\mathrm{I}^{2}=50.29 \% ; \mathrm{p} \leq 0.001\right)$ (figure 10$)$.

Likewise, studies included in obesity estimation among adults in Ethiopia were adjusted with trim and fill analysis and only one study was imputed for missing studies. However, after adjustment, the estimated pooled prevalence of obesity was found to be $5.44 \%$ (95\% CI $4.37 \%$ to $6.51 \%)$. This finding is similar with the unadjusted prevalence rate of obesity, but with different levels of heterogeneity among the studies in the random-effects model analysis $\left(\mathrm{I}^{2}=3.71 \%, \mathrm{p} \leq 0.001\right)$ (figure 11$)$.

\section{DISCUSSION}

This systematic review and meta-analysis were conducted to estimate the pooled prevalence of overweight and obesity among adults in Ethiopia. The prevalence of overweight reported in the country ranges from $4.7 \%^{42}$ to $40.1 \%{ }^{41}$ This difference could be due to differences in the study population because unlike the first study which was conducted on the nutritional status of lactating mothers, the second study was conducted among officebased urban civil servants. Office-based civil servants are one of the highest groups for overweight and obesity due to their occupational exposure to sedentary type lifestyles. $^{48} 49$

Besides, the prevalence of obesity reported in the country ranges from $1.6 \%{ }^{42}$ to $16.2 \% .^{34}$ This discrepancy might be due to differences in the study population. The first finding that is $1.6 \%$ were reported from the study in lactating mothers and the later, $16.2 \%$ was reported from a study conducted among the general adult population and only in the urban setting, a well-known risk factor for overweight and obesity because people living in urban settings are at increased risk of sedentary type lifestyles and consumption of more energy-dense foods. ${ }^{5051}$ On the other hand, lactating mothers have increased nutritional demand and are at greater risk of undernutrition if the nutritional requirements are not properly fulfilled. ${ }^{52} 53$

In this study, the estimated pooled prevalence of overweight among adults was $20.4 \%$. However, due to the presence of publication bias, after adjustment with the trim and fill analysis, the estimated prevalence rate was changed to $19 \%$. Besides, the estimated pooled prevalence of obesity among adults in Ethiopia was $5.4 \%$. These findings are higher than the 2011 and 2016 Ethiopian demographic and health survey reports indicating an increasing trend in the prevalence rates of overweight and obesity in Ethiopia. ${ }^{14}$ The results are in line with a meta-analysis in the Asian Pacific region which has reported that the prevalence of overnutrition was estimated at $23 \% .^{54}$

A consistent finding has been also reported from a study in Ghana that the national prevalence of overweight was estimated at $25.4 \%$. However, obesity in the Ghanaian study was significantly higher $(17.1 \%)$ than the current study. ${ }^{55}$ In addition to the Ghanaian study, a study in Iran has shown that the prevalence of obesity in adults of Iran was $21.4 \%$ based on a meta-analysis of studies in the country. ${ }^{56}$ Another meta-analysis in Iran among military personnel has also indicated that the pooled prevalence of overweight and obesity was $41 \%$ and $13 \%$, respectively, significantly higher values than our study findings. ${ }^{57}$

These discrepancies might be due to differences in the study population, the developmental level of these countries and the educational level of participants. One of the Iranian studies was conducted among military personnel and may not be representative of the national prevalence of overweight and obesity because the high prevalence rate might be occupation related. ${ }^{57}$ This might be also due to their capacity of purchasing more energy-dense foods as witnessed from studies in both developed and low/middle-income countries that high-income households purchased foods in bulk and were more likely to overconsume these foods. ${ }^{58-60}$

Likewise, the prevalence of overweight and obesity in Ethiopia is significantly lower than a study in Spain that the estimated prevalence of overweight in the Spanish adult population was $39.3 \%$ and obesity was $21.6 \% .{ }^{61}$ The Spanish result is in line with WHO global report that $39 \%$ of adults aged 18 years and over were overweight in 2016 , and $13 \%$ were obese. ${ }^{7}$

There was a significant level of heterogeneity among the primary studies included in this systematic review and meta-analysis. Thus, a subgroup analysis was conducted

Egger's test
\begin{tabular}{r|rrrrrr} 
\\
std_Eff & Coef. & std. Err. & $t$ & $P>|t|$ & {$[95 \%$ Conf. Interva1] } \\
\hline slope & .8714913 & .4245854 & 2.05 & 0.059 & -.0391538 & 1.782136 \\
bias & 5.452998 & .8718187 & 6.25 & 0.000 & 3.583133 & 7.322863 \\
\hline
\end{tabular}

Figure 9 Egger's test for detection of publication bias for studies included in obesity. 
Trim and fill analysis for the pooled prevalence of overweight

Meta-ana7ysis

\begin{tabular}{|c|c|c|c|c|c|c|}
\hline & $\begin{array}{r}\text { Pooled } \\
\text { Est }\end{array}$ & $\begin{array}{r}95 \% \\
\text { Lower }\end{array}$ & $\begin{array}{l}\text { CI } \\
\text { Upper }\end{array}$ & $\begin{array}{r}\text { Asym } \\
\text { z_va } 7 \text { ue }\end{array}$ & $\begin{array}{l}\text { totic } \\
\text { p_value }\end{array}$ & $\begin{array}{l}\text { No. of } \\
\text { studies }\end{array}$ \\
\hline & $\begin{array}{l}14.105 \\
20.439\end{array}$ & $\begin{array}{l}13.568 \\
16.690\end{array}$ & $\begin{array}{l}14.641 \\
24.189\end{array}$ & $\begin{array}{l}51.500 \\
10.685\end{array}$ & $\begin{array}{l}0.000 \\
0.000\end{array}$ & 1 \\
\hline
\end{tabular}

Test for heterogeneity: $Q=540.744$ on 13 degrees of freedom $(p=0.000)$ Moment-based estimate of between studies variance $=47.477$

Trimming estimator: Linear

Meta-analysis type: Random-effects model

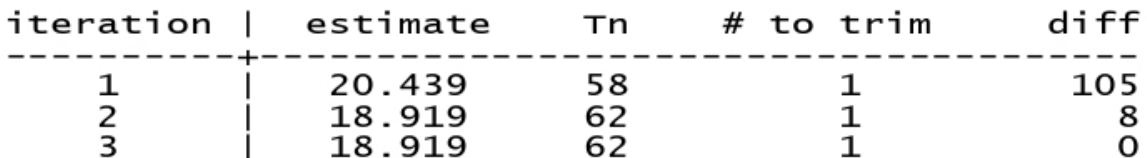

Fi 17 ed

Meta-ana7ysis

\begin{tabular}{|c|c|c|c|c|c|c|}
\hline \multirow{2}{*}{ Method } & \multirow{2}{*}{$\begin{array}{r}\text { Pooled } \\
\text { Est }\end{array}$} & \multicolumn{2}{|c|}{$95 \%$ CI } & \multicolumn{2}{|c|}{ Asymptotic } & \multirow{2}{*}{$\begin{array}{l}\text { No. of } \\
\text { studies }\end{array}$} \\
\hline & & Lower & Upper & z_va 7 ue & p_va 7 ue & \\
\hline & $\begin{array}{l}13.916 \\
19.016\end{array}$ & $\begin{array}{l}13.382 \\
15.289\end{array}$ & $\begin{array}{l}14.449 \\
22.743\end{array}$ & $\begin{array}{l}51.106 \\
10.000\end{array}$ & $\begin{array}{l}0.000 \\
0.000\end{array}$ & 1 \\
\hline
\end{tabular}

Test for heterogeneity: $Q=581.975$ on 14 degrees of freedom $(p=0.000)$ Moment-based estimate of between studies variance $=50.285$

Figure 10 Trim-and-fill analysis for the prevalence of overweight among adults in Ethiopia.

\section{Trim and fill analysis for the pooled prevalence of obesity}

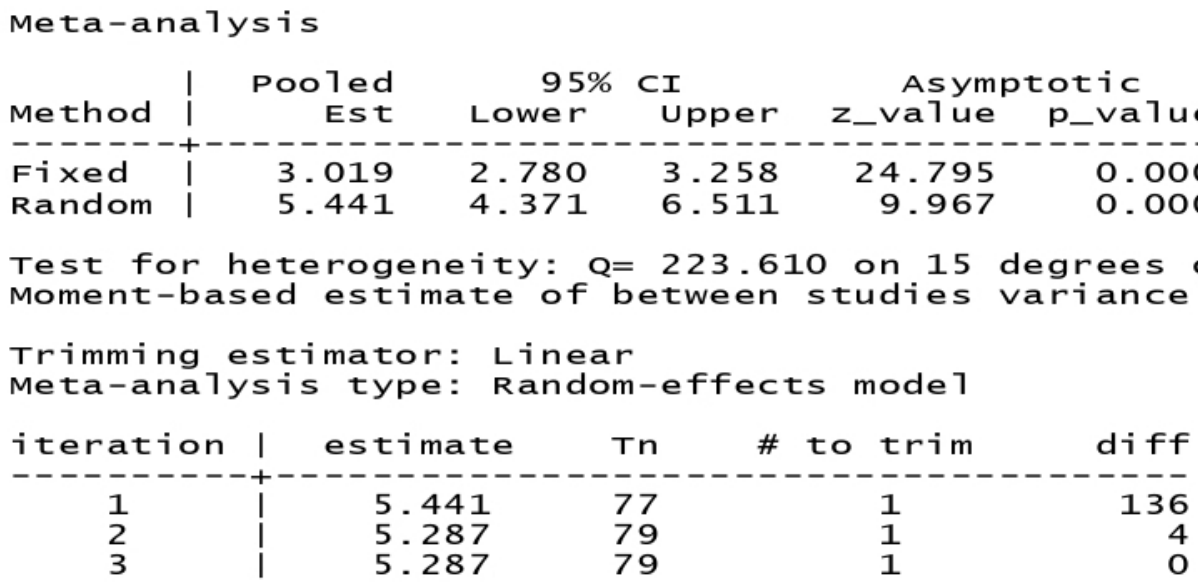

Fi 11 ed

Meta-anatysis

\begin{tabular}{|c|c|c|c|c|c|c|}
\hline \multirow[b]{2}{*}{ Method } & \multirow{2}{*}{$\begin{array}{r}\text { Pooled } \\
\text { Est }\end{array}$} & \multicolumn{2}{|c|}{$95 \%$ CI } & \multicolumn{2}{|c|}{ Asymptotic } & \multirow{2}{*}{$\begin{array}{l}\text { No. of } \\
\text { studies }\end{array}$} \\
\hline & & Lower & upper & z_value & p_va 7 ue & \\
\hline & $\begin{array}{l}3.013 \\
5.309\end{array}$ & $\begin{array}{l}2.774 \\
4.240\end{array}$ & $\begin{array}{l}3.251 \\
6.377\end{array}$ & $\begin{array}{r}24.752 \\
9.737\end{array}$ & $\begin{array}{l}0.000 \\
0.000\end{array}$ & 17 \\
\hline
\end{tabular}

Test for heterogeneity: $Q=227.350$ on 16 degrees of freedom ( $p=0.000)$ Moment-based estimate of between studies variance $=3.754$

Figure 11 Trim-and-fill analysis for the prevalence of obesity among adults in Ethiopia. 
through stratification using study year, residence, study setting and sample size in order to identify the sources of heterogeneity to the pooled prevalence of overweight and obesity. The prevalence of overweight was found to be higher in some groups; $22.6 \%$ in studies conducted since $2015,22.4 \%$ in studies conducted only in urban settings, $20.4 \%$ in institution-based settings and $24.4 \%$ in studies with a sample size of less than or equal to 384 participants compared with their counterparts. This indicates that overweight has increased among adults in Ethiopia compared with previous studies. ${ }^{14}$

Besides, the prevalence of obesity was found to be $6.9 \%$ in studies conducted since $2015,6.2 \%$ in studies conducted only in urban settings, $6.4 \%$ in institutionbased settings, and $9.6 \%$ in studies with a sample size of less than or equal to 384 participants. This means the prevalence of overweight and obesity is increasing from time to time especially among urban residents. However, no study was found involving rural participants only. The majority of the studies were conducted in urban areas and only two studies were conducted involving participants from both urban and rural settings. If sufficient studies were found in rural areas the results might not have been like this (table 1 ).

This is due to the fact that the prevalence rate of overweight and obesity is significantly different in rural and urban settings across low-income and middle-income countries with the highest rates occurring in urban settings. For example, the Ghanaian study has reported a higher prevalence of overweight (27.2\% in urban and $16.7 \%$ in rural), and obesity (20.6\% in urban and $8.0 \%$ in rural settings) among urban than rural residents. ${ }^{55}$ Similar findings have been reported from the Ethiopian demographic and health survey 2016 report and from other African countries that the prevalence rate of overweight and obesity is higher among urban residents compared with the rural residents. ${ }^{141762}$

This finding might be due to the rapid demographic, epidemiological and nutrition transitions in Ethiopia because urbanisation and a shift in nutritional habits are the major known factors which predispose people to overweight and obesity. ${ }^{8}$ The other reason could be due to differences in lifestyle of urban dwellers as compared with the rural residents. Unlike rural residents who are usually more actively involved in a less sedentary lifestyle and more laborious activities, the occupation of urban dwellers might result in sedentary type lifestyles among the adult population. ${ }^{63-65}$

\section{CONCLUSION}

The prevalence rate of overweight and obesity is high in Ethiopia compared with the previous studies. The prevalence of overweight and obesity was higher in studies conducted only in urban settings compared with studies conducted in both urban and rural settings. Furthermore, the rates were also higher in studies conducted since 2015 and in small sample size studies. Hence, large scale awareness creation campaigns and situation-based and context-specific preventive strategies need to be designed to reduce the burden of overweight and obesity in the country.

\section{Twitter Biruk Beletew Abate @biruk}

Contributors AMK and BBA developed the study protocol and were involved in the design, selection of study, data extraction, statistical analysis and writing the initial drafts of the manuscript. MKW was involved in data extraction, quality assessment, statistical analysis and revising. AMK and BBA prepared and edited the final manuscript. All authors have read and approved the submission of the final version of the manuscript.

Funding The authors have not declared a specific grant for this research from any funding agency in the public, commercial or not-for-profit sectors.

Competing interests None declared.

Patient consent for publication Not required.

Provenance and peer review Not commissioned; externally peer reviewed.

Data availability statement All data relevant to the study are included in the article or uploaded as online supplementary information. The data used during this systematic review and meta-analysis are available within the article and the supporting file.

Open access This is an open access article distributed in accordance with the Creative Commons Attribution Non Commercial (CC BY-NC 4.0) license, which permits others to distribute, remix, adapt, build upon this work non-commercially, and license their derivative works on different terms, provided the original work is properly cited, appropriate credit is given, any changes made indicated, and the use is non-commercial. See: http://creativecommons.org/licenses/by-nc/4.0/.

\section{ORCID iDs}

Ayelign Mengesha Kassie http://orcid.org/0000-0003-1505-9390

Biruk Beletew Abate http://orcid.org/0000-0003-0833-2504

Mesfin Wudu Kassaw http://orcid.org/0000-0002-6327-7723

\section{REFERENCES}

1 Fanzo J, Hawkes C, Udomkesmalee E, et al. Global nutrition report: shining a light to Spur action on nutrition, 2018.

2 Doak CM, Wijnhoven TMA, Schokker DF, et al. Age standardization in mapping adult overweight and obesity trends in the who European region. Obes Rev 2012;13:174-91.

3 World Health organization. Global database on body mass index.BMI classification. Geneva: WHO, 2004.

4 Dobbs R, Sawers C, Thompson F, et al. Overcoming obesity: an initial economic analysis. 2014. McKinsey \& Company, 2014: 1-106. www mckinsey com/mgi

5 Morgen CS, Sørensen TIA. Obesity: global trends in the prevalence of overweight and obesity. Nat Rev Endocrinol 2014;10:513-4.

6 , Afshin A, Forouzanfar MH, et al, GBD 2015 Obesity Collaborators. Health effects of overweight and obesity in 195 countries over 25 years. N Engl J Med 2017;377:p 13-27.

7 World health organization. Overweight and obesity report fact sheet. Available: https://www.who.int/news-room/fact-sheets/detail/ obesity-and-overweight [Accessed 3 Mar 2020].

8 Kuate Defo B, Defo BK. Demographic, epidemiological, and health transitions: are they relevant to population health patterns in Africa? Glob Health Action 2014;7:22443.

9 Yatsuya H, Li Y, Hilawe EH, et al. Global trend in overweight and obesity and its association with cardiovascular disease incidence. Circ J 2014;78:CJ-14-0850:2807-18.

10 Berrington de Gonzalez A, Hartge P, Cerhan JR, et al. Body-Mass index and mortality among 1.46 million white adults. N Engl J Med 2010;363:2211-9.

11 World Health Organization. Obesity and overweight. fact sheet number 311. World Health Organisation, 2014: 1-5.

12 Bovet P, Chiolero A, Gedeon J. Health effects of overweight and obesity in 195 countries. N Engl J Med 2017;377:1495-6.

13 Bhurosy T, Jeewon R. Overweight and obesity epidemic in developing countries: a problem with diet, physical activity, or socioeconomic status? Scientific World Journal 2014;2014:964236

14 Central Statistical Agency (CSA) [Ethiopia], ICF International. Ethiopia demographic and health survey. Addis Ababa, Ethiopia, and Rockville, Maryland, USA: CSA and ICF, 2016. 
15 Sarma H, Saquib N, Hasan MM, et al. Determinants of overweight or obesity among ever-married adult women in Bangladesh. BMC Obes 2016;3:13.

16 Benkeser RM, Biritwum R, Hill AG. Prevalence of overweight and obesity and perception of healthy and desirable body size in urban, Ghanaian women. Ghana Med J 2012;46:66-75.

17 Diendéré J, Kaboré J, Somé JW, et al. Prevalence and factors associated with overweight and obesity among rural and urban women in Burkina Faso. Pan Afr Med J 2019;34:199.

18 Pengpid S, Peltzer K. Prevalence and correlates of underweight and overweight/obesity among women in India: results from the National family health survey 2015-2016. Diabetes Metab Syndr Obes 2019;12:647-53.

19 Hruschka DJ, Brewis AA. Absolute wealth and world region strongly predict overweight among women (ages 18-49) in 360 populations across 36 developing countries. Econ Hum Biol 2013;11:337-44.

20 Bishwajit G. Household wealth status and overweight and obesity among adult women in Bangladesh and Nepal. Obes Sci Pract 2017;3:185-92

21 Force U. Screening and interventions for overweight and obesity in adults. Rockville, MD: Agency for Healthcare Research and Quality, 2003

22 Regassa N, Stoecker BJ. Contextual risk factors for maternal malnutrition in a food-insecure zone in southern Ethiopia. J Biosoc Sci 2012;44:537-48.

23 Ahmed K, Abrha S, Page A, et al. Trends and determinants of underweight and Overweight/Obesity among urban Ethiopian women from 2000 to $2016,2020$.

24 World Health organization (who). global database on body mass index.BMI Classification. In: . Geneva: WHO, 2004.

25 Institute JB. Critical appraisal tools. The University of Adelaide, 2017. Available: joannabriggs org/research/criticalappraisal-tools html[Accessed 20 Jan 2017].

26 Huedo-Medina TB, Sánchez-Meca J, Marín-Martínez F, et al. Assessing heterogeneity in meta-analysis: Q statistic or 12 index? Psychol Methods 2006;11:193-206.

27 Higgins J, Green S. Assessing risk of bias in included studies. Cochrane Handbook for systematic reviews of interventions. Version 5.1. 0;, 2011.

28 Egger M, Davey-Smith G, Altman D. Systematic reviews in health care: meta-analysis in context. John Wiley \& Sons, 2008.

29 Shi L, Lin L. The trim-and-fill method for publication bias: practical guidelines and recommendations based on a large database of meta-analyses. Medicine 2019;98:e15987.

30 StataCorp L. Stata statistical software. Version release 14. College Station, TX, 2015.

31 Moher D, Liberati A, Tetzlaff J, et al. Preferred reporting items for systematic reviews and meta-analyses: the PRISMA statement. Ann Intern Med 2009;151:264-9.

32 Awoke A, Awoke T, Alemu S, et al. Prevalence and associated factors of hypertension among adults in Gondar, Northwest Ethiopia: a community based cross-sectional study. BMC Cardiovasc Disord 2012;12:113.

33 Janakiraman B, Abebe SM, Chala MB, et al. Epidemiology of general, central obesity and associated Cardio-Metabolic risks among university employees, Ethiopia: a cross-sectional study. diabetes, metabolic syndrome and obesity: targets and therapy. 13, 2020.

34 Moges B, Amare B, Fantahun B, et al. High prevalence of overweight, obesity, and hypertension with increased risk to cardiovascular disorders among adults in Northwest Ethiopia: a cross sectional study. BMC Cardiovasc Disord 2014;14:155.

35 Dagne S, Gelaw YA, Abebe Z, et al. Factors associated with overweight and obesity among adults in northeast Ethiopia: a crosssectional study. Diabetes Metab Syndr Obes 2019;12:391-9.

36 Mekonnen T, Animaw W, Seyum Y. Overweight/obesity among adults in north-western Ethiopia: a community-based cross sectional study. Arch Public Health 2018;76:18.

37 Amare B, Moges B, Moges F, et al. Nutritional status and dietary intake of urban residents in Gondar, Northwest Ethiopia. BMC Public Health 2012;12:752.

38 Abera D, Boltena MT. Determinants of obesity among working adults in Wolaita Sodo town, southern Ethiopia. International Journal of African and Asian Studies;39:14-21. https://iiste.org/Journals/index. php/JAAS/article/view/39176

39 Darebo T, Mesfin A, Gebremedhin S. Prevalence and factors associated with overweight and obesity among adults in Hawassa City, southern Ethiopia: a community based cross-sectional study. BMC Obes 2019;6:8
40 Gutema BT, Chuka A, Kondale M, et al. The burden of malnutrition among adults residing in Arba Minch health and demographic surveillance site (HDSS): a who steps survey. J Nutr Metab 2020;2020:6986830

41 Yohannes M. Prevalence of overweight and obesity among officebased urban civil servants in southern nations, nationalities and peoples' region, ethiopia. Ethiop Med J 2019;57.

42 Desisa Hundera T, Hundera TD, et al. Nutritional status and associated factors among lactating mothers in Nekemte referral hospital and health centers, Ethiopia. IJNFS 2015;4:216-22.

43 Hussein M. Overs nitration and associated factors among women of reproductive age group in Jigjiga somal, National regional state eastern Ethiopia. Haramaya University, 2015.

44 Kahsay AB, Gebru HB, Maeruf H. Prevalence and factors associated with overweight/Obesity in public servants, Tigray, Ethiopia: the case of Mekelle City. JMST 2019;7:39-46.

45 Yibeltal T, Charles T, Uriyoan C. The rising Overweight-obesity and its socio-demographic correlates in Addis Ababa, Ethiopia, 2000-2011, 2013.

46 Mekonnen W, Bogale A. Determinants of obesity among women of childbearing age in urban areas of Ethiopia. Age 2017:15:993.

47 Abrha S, Shiferaw S, Ahmed KY. Overweight and obesity and its socio-demographic correlates among urban Ethiopian women: evidence from the 2011 EDHS. BMC Public Health 2016;16:636.

48 Simkhada P, Poobalan A, Simkhada PP, et al. Knowledge, attitude, and prevalence of overweight and obesity among civil servants in Nepal. Asia Pac J Public Health 2011;23:507-17.

49 Bogale KA, Zewale TA. Determinant factors of overweight/obesity among federal Ministry civil servants in Addis Ababa, Ethiopia: a call for sector-wise occupational health program. BMC Res Notes 2019;12:449.

50 Jitnarin N, Kosulwat V, Rojroongwasinkul N, et al. Risk factors for overweight and obesity among Thai adults: results of the National Thai food consumption survey. Nutrients 2010;2:60-74.

51 Sola AO, Steven AO, Kayode JA, et al. Underweight, overweight and obesity in adults Nigerians living in rural and urban communities of Benue state. Ann Afr Med 2011:10:139-43.

52 Neville M. Lactation: physiology, nutrition, and breast-feeding. Springer Science \& Business Media, 2013.

53 Connor KL, Vickers MH, Beltrand J, et al. Nature, nurture or nutrition? impact of maternal nutrition on maternal care, offspring development and reproductive function. J Physiol 2012;590:2167-80.

54 Peng W, Mu Y, Hu Y, et al. Double burden of malnutrition in the AsiaPacific Region-A systematic review and meta-analysis. J Epidemiol Glob Health 2019;10:16.

55 Ofori-Asenso R, Agyeman AA, Laar A, et al. Overweight and obesity epidemic in Ghana-a systematic review and meta-analysis. BMC Public Health 2016;16:1239.

56 Vaisi-Raygani A, Mohammadi M, Jalali R, et al. The prevalence of obesity in older adults in Iran: a systematic review and meta-analysis. BMC Geriatr 2019;19:1-9.

57 Salimi Y, Taghdir M, Sepandi M, et al. The prevalence of overweight and obesity among Iranian military personnel: a systematic review and meta-analysis. BMC Public Health 2019;19:162.

58 McEwen J, Russell EM, Stewart S. Needs assessment in Scotland: collaboration in public health. Public Health 1995;109:179-85.

59 Abdu Z, Kabeta T, Dube L, et al. Prevalence and associated factors of depression among prisoners in Jimma town prison, South West Ethiopia. Psychiatry J 2018;2018:5762608:1-10.

60 Kamarulzaman A, Reid SE, Schwitters A, et al. Prevention of transmission of HIV, hepatitis B virus, hepatitis $\mathrm{C}$ virus, and tuberculosis in prisoners. The Lancet 2016;388:1115-26.

61 Aranceta-Bartrina J, Pérez-Rodrigo C, Alberdi-Aresti G, et al. Prevalence of general obesity and abdominal obesity in the Spanish adult population (aged 25-64 years) 2014-2015: the ENPE study. Revista Española de Cardiología 2016:69:579-87.

62 Chukwuonye II, Chuku A, John C, et al. Prevalence of overweight and obesity in adult Nigerians - a systematic review. Diabetes Metab Syndr Obes 2013:6:43.

63 Chatterji M, Baldwin AM, Prakash R, et al. Public health response to a measles outbreak in a large correctional facility, Queensland. Commun Dis Intell. 2014;38:E294-7.

64 Ojiambo RM, Easton C, Casajús JA, et al. Effect of urbanization on objectively measured physical activity levels, sedentary time, and indices of adiposity in Kenyan adolescents. J Phys Act Health 2012;9:115-23

65 Assah FK, Ekelund U, Brage S, et al. Urbanization, physical activity, and metabolic health in sub-Saharan Africa. Diabetes Care 2011;34:491-6. 